\title{
Professional navigation: A comparative study of two Canadian models
}

by Lise Fillion, Sandra Cook, Anne-Marie Veillette, Marie de Serres, Michèle Aubin, François Rainville, Margaret Fitch and Richard Doll

\section{Abstract}

For many cancer control programs, cancer navigation has emerged as a specific strategy to improve access to supportive care and the patients' experience of cancer care. This study contributes to a

\section{About the authors}

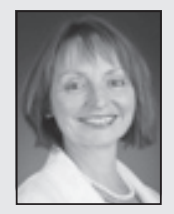

Lise Fillion, RN, PhD (Psychology), Professor, Faculty of Nursing, Laval University, Cancer Research Centre of Laval University, Hôtel-Dieu de Québec

Address correspondence to: Lise Fillion, Cancer Research Center of Laval University, Hôtel-Dieu de Québec, 9 rue McMahon, Québec, QC G1R 2J6. Tel.: 418-525-4444 ext. 15754; Fax: 418-691-2920, Email: Lise.Fillion@fsi.ulaval.ca
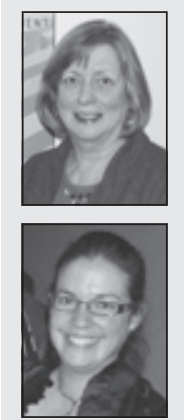

Anne-Marie Veillette, Anth, MA, Research Coordinator, Cancer Research Centre of Laval University, Hôtel-Dieu de Québec

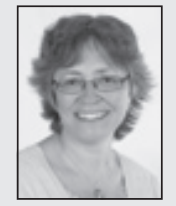

Marie de Serres, RN, MSc, Clinical Nurse Specialist, CON(C), CHUQ Hôtel-Dieu de Québec

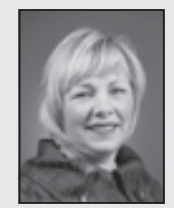

Michèle Aubin, MD, PhD, FCFP, CCFP, Laval University Chair of Palliative Care, Faculty of Medicine, Laval University, Unité de Médecine Familiale-Laval, CSSS Vieille-Capitale

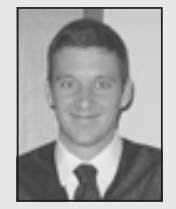

François Rainville, MSW, Social Worker, CHUQ Cancer Research Centre of Laval University, HôtelDieu de Québec

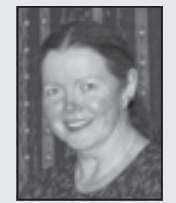

Margaret Fitch, RN, MScN, PhD, Head, Oncology Nursing, Co-director, Patient and Family Support Program, Odette Cancer Centre, Sunnybrook Health Sciences Centre

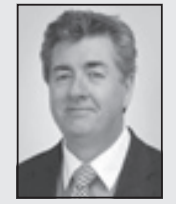

Richard Doll, MSW, MSc, Director, Sociobehavioural Research Centre, and Provincial Leader, Cancer Rehabilitation, BC Cancer Agency better understanding of professional navigation by comparing two Canadian models: Quebec's Pivot Nurse in Oncology (PNO) and Nova Scotia's Cancer Patient Navigator (CPN). Qualitative interviews were conducted with professional navigators, patients and family members, front-line staff, physicians and health administrators (interviews: $n=49$; focus groups: $n=10$ ). The two models were analyzed using the professional navigation framework (Fillion et al., 2012). Although the models are different, results show that professional navigators in both programs perform similar functions and face similar challenges. This study highlights the complexity and the value of cancer navigation and recommends relevant actions to optimize its management within the health care system.

As cancer treatments and approaches get increasingly complex, patients and their family have to learn to navigate their way through a fragmented health care system. Cancer control programs acknowledge the necessity to improve continuity of care and patient's quality of life in many countries. Cancer navigation programs have emerged as a specific strategy to improve patients' experience of cancer care (Doll et al., 2007; Fitch, 2008; Haggerty et al., 2003). In Canada, the Canadian Partnership Against Cancer Corporation (CPACC) supports the implementation of cancer navigation as a crucial component of improving clinical and supportive cancer care, and proposes three modes or types of cancer navigation: self-navigation, through virtual or online aids; lay navigation, which is led by a volunteer or a peer cancer survivor; and professional navigation, which is carried out by paid health care providers. Self-, lay and professional navigation have different responsibilities, role expectations and intended outcomes (CPACC, 2010). In an effort to better understand one of these modes, professional navigation, this work focuses on the comparison of two well implemented Canadian professional navigation programs.

\section{Professional cancer navigation}

Empirical work has described the implementation of different Canadian professional-led models of cancer navigation (Cancer Care Nova Scotia, 2004; Fillion et al., 2006; Plante \& Joannette, 2009a, 2009b; Skrutkowski et al., 2008; Tremblay, 2008). Parker et al. (2010) have noted that to date, several approaches to describe and define the professional navigator's role have been proposed, but that few consensuses are observed. Thorne and Truant (2010), focusing on the organizational dimension of the role, have described professional navigation as a solution to "band-aid" problems created by the way the cancer care system is fragmented and not integrated. Other authors have described navigators as case managers in cancer settings (Lantz, Keeton, Romano \& Degroff, 2004). However, while organizational navigation and basic case-management may help to improve delays and management through the cancer care continuum, it does not necessarily make the cancer journey connected and coherent from the patient's perspective. A lack of person-centred supportive care is still noticed (Fitch, 2008).

In Canada, professional navigation generally corresponds to a more comprehensive medical or social model of case management that values humanizing the care trajectory and empowering the patient (Fillion et al., 2006). This role is, in fact, quite complex, and includes organizational functions and clinical ones (Doll et al., 2007).

Acknowledging a bi-dimensional structure, one dimension contributing to improvement of health care continuity and one dimension aiming at empowering cancer patients and family to deal with cancer, Fillion et al. (2012) propose a comprehensive definition of professional navigation. The first dimension corresponds to "facilitating continuity of care". The construct of continuity of care was 
adapted by Fillion et al. (2012) from the theoretical model proposed by Haggerty (2003) to include three sub-dimensions, which are informational continuity, management continuity, and relational continuity. The second dimension called "promoting patient and family empowerment", integrates three different constructs, which are active coping (Carver, Scheier \& Weintraub, 1989), cancer selfmanagement (Bulsara, Styles, Ward \& Bulsara, 2006), and supportive care (Fitch, 2008) (for further details, see Fillion et al., 2012).

In its validation process, the bi-dimensional navigation framework content reached consensus among professional navigators, experts, managers and clinicians, as well as cancer patients and their significant others from across Canada (Fillion et al., 2012). The framework recognizes that the functions encompass a variety of organizational and clinical functions, related respectively to each dimension described above, that few professionals other than oncology nurses or well trained social workers in psychosocial oncology are well suited to perform.

Involving specialized oncology nurses as professional navigators, two provincial professional cancer navigation programs, the "infirmière pivot en oncologie", or Pivot Nurse in Oncology (PNO) in Quebec (de Serres \& Beauchesne, 2000) and the Cancer Patient Navigator (CPN) program in Nova Scotia (Cancer Care Nova Scotia, 2004), were implemented in the early 2000s. In both models, PNOs and CPNs are nurses and have completed certification training in oncology. They work with newly diagnosed patients, those undergoing treatment and in follow-up, as well as cancer survivors. The PNOs and CPNs offer patients, families and caregivers assistance through the maze of options and services needed in order to achieve the best possible outcomes and quality of life, through all phases of the cancer experience (see Fillion et al. (2012)'s model for concrete examples of key functions).

The differences between the two models are currently still unknown. In describing their bi-dimensional navigation framework, Fillion et al. (2012) have shown that both PNOs and CPNs have a very similar role, but have not described how the application of their role may differ while working in their respective settings. The objective of this study was to contribute to a better understanding of cancer navigation by comparing these two well-implemented models of professional navigation located in Quebec and Nova Scotia.

\section{Method}

\section{Research approach}

To have a better understanding of cancer navigation, this qualitative descriptive study used a multiple-case design (Yin, 1994) involving two cases: 1) Pivot nurse in oncology/PNO in the larger Quebec City area, and 2) Cancer patient navigator/CPN in Nova Scotia. The purpose of this study was to compare PNOs and CPNs, and determine whether there were major differences between the two studied cases, with a focused evaluation process (Fillion et al., 2011; Patton, 1997) and using Fillion et al.'s (2012) bi-dimensional conceptual model as a reference (see Table 1).

\section{Participants and recruitment}

The intentional sample gathered eight groups of participants: 1) PNOs, 2) CPNs, 3) medical oncology specialists, 4) nurses and oncology staff, 5) administrators, 6) family physicians, 7) cancer patients, and 8) family and significant others. Groups 1, 3, 4, 5, 6, 7 and 8 have participated in Quebec, and groups 2 and 5 participated in Nova Scotia. A non-probabilistic information-oriented sampling of participants was used to gather rich opinions and experiences.

The CPNs, PNOs and administrators from Nova Scotia and Quebec contributed to the recruitment, elaborating lists of eligible participants who were contacted by phone by the research team. Also, cancer patients contributed to the recruitment process by inviting their family members to participate. All interested participants were contacted by phone by a member of the research team. All participants signed an information and consent form. This research project received approval by the ethical board of each participating establishment.

\section{Data collection}

A multimodal data collection was completed: 1) documents (literature review, CPNs/PNOs tools and resources); 2) individual interviews $(n=49)$; and 3$)$ focus groups $(n=10)$. For individual interviews and focus groups discussion guidelines (see appendices 1 and 2 for some examples), questions were framed according to the bi-dimensional professional navigation framework developed by Fillion et al. (2012) and a focused evaluation process (Fillion et al., 2011; Patton, 1997).

\begin{tabular}{|c|c|}
\hline Dimensions & Concepts \\
\hline \multirow{3}{*}{$\begin{array}{c}\text { Facilitating } \\
\text { continuity } \\
\text { of care } \\
\text { (experience of care } \\
\text { as coherent } \\
\text { and connected) } \\
\text { Organizational } \\
\text { functions of the role } \\
\text { (Dimension } \\
\text { health-system-oriented) }\end{array}$} & $\begin{array}{l}\text { Informational continuity } \\
\text { Use of information, disease or person focused, to make current care appropriate for each individual. } \\
\text { Information is relevant to link care from one provider to another and from one healthcare event to another } \\
\text { (Haggerty et al., 2003). }\end{array}$ \\
\hline & $\begin{array}{l}\text { Management continuity } \\
\text { A consistent and coherent approach to the management of cancer that is responsive to a patient's changing } \\
\text { needs. Providing a sense of predictability and security in future care for both patients and providers } \\
\text { (Haggerty et al., 2003). }\end{array}$ \\
\hline & $\begin{array}{l}\text { Relational continuity } \\
\text { A therapeutic relationship between a patient and at least one provider, who develops accumulated } \\
\text { knowledge of the patient as a person and bridges the past to current and future care (Haggerty et al., 2003). }\end{array}$ \\
\hline \multirow{3}{*}{$\begin{array}{c}\text { Promoting patient and } \\
\text { family empowerment } \\
\text { (care providers as } \\
\text { supportive partners } \\
\text { in care) } \\
\text { Clinical functions } \\
\text { of the role } \\
\text { (Dimension } \\
\text { patient-centred) }\end{array}$} & $\begin{array}{l}\text { Active coping } \\
\text { Process of taking active steps to try to remove or circumvent the stressor or to ameliorate its effects (Carver } \\
\text { et al., 1989). }\end{array}$ \\
\hline & $\begin{array}{l}\text { Cancer self-management } \\
\text { Supporting the person and family and reinforcing his or her ability to accept the illness and regain control, } \\
\text { regardless of prognosis (Bulsara et al., 2006). }\end{array}$ \\
\hline & $\begin{array}{l}\text { Supportive care } \\
\text { Providing the necessary services as defined by those living with or affected by cancer to meet their physical, } \\
\text { informational, practical, emotional, psychological, social, and spiritual needs (Fitch, 2008). }\end{array}$ \\
\hline
\end{tabular}




\begin{tabular}{|c|c|c|c|c|c|c|c|}
\hline & $\begin{array}{l}\text { CPNs from } \\
\text { Nova Scotia } \\
(n=5)\end{array}$ & $\begin{array}{l}\text { Managers } \\
\text { from Nova } \\
\text { Scotia }(n=5)\end{array}$ & PNOs $(n=21)$ & $\begin{array}{l}\text { Managers } \\
\text { from Quebec } \\
(n=8)\end{array}$ & $\begin{array}{l}\text { Specialized } \\
\text { medical } \\
\text { doctors }(n=5)\end{array}$ & $\begin{array}{l}\text { Family } \\
\text { doctors } \\
(n=11)\end{array}$ & $\begin{array}{l}\text { Other } \\
\text { oncology } \\
\text { workers }(n=27)\end{array}$ \\
\hline \multicolumn{8}{|l|}{ Gender } \\
\hline Women & $5(100 \%)$ & $5(100 \%)$ & 21 (100\%) & $6(75 \%)$ & $3(60 \%)$ & $5(45 \%)$ & 25 (93\%) \\
\hline Men & $0(0 \%)$ & $0(0 \%)$ & $0(0 \%)$ & $2(25 \%)$ & 2 (40\%) & $6(55 \%)$ & $2(7 \%)$ \\
\hline Age, $M(S D)$ & $46.00(9.20)$ & $47.00(10.15)$ & $43.10(9.36)$ & $47.00(6.35)$ & $43.80(10.40)$ & $48.82(6.94)$ & $47.70(8.68)$ \\
\hline \multicolumn{8}{|l|}{ Years of experience } \\
\hline Total, $M(S D)$ & 20.25 (10.69) & $17.75(8.62)$ & $21.81(10.55)$ & $27.75(6.09)$ & $14.90(10.51)$ & $22.73(8.11)$ & $23.15(9.24)$ \\
\hline In oncology, $M(S D)$ & $6.63(5.96)$ & $9.75(7.85)$ & $10.24(9.96)$ & $15.75(11.13)$ & $15.80(9.31)$ & $18.50(7.87)$ & $9.43(7.81)$ \\
\hline $\begin{array}{l}\text { In current position, } \\
M(S D)\end{array}$ & $4.63(2.63)$ & $7.50(8.96)$ & $2.17(1.97)$ & $2.88(2.10)$ & $13.90(10.62)$ & $20.73(10.12)$ & $8.50(7.36)$ \\
\hline $\begin{array}{l}\text { Estimated number of } \\
\text { new cancer patients } \\
\text { followed per year, } M \\
(S D)\end{array}$ & $\begin{array}{c}228.33 \\
(106.81)\end{array}$ & Doesn’t apply & 161.89 (106.21) & Doesn't apply & $250.00(212.13)$ & $53.18(85.12)$ & Doesn't apply \\
\hline \multicolumn{8}{|l|}{ Education } \\
\hline $\begin{array}{l}\text { Registered nurse } \\
\text { diploma (Nova Scotia) }\end{array}$ & $2(40 \%)$ & $0(0 \%)$ & $0(0 \%)$ & $0(0 \%)$ & $0(0 \%)$ & $0(0 \%)$ & $0(0 \%)$ \\
\hline College (Quebec) & $0(0 \%)$ & $0(0 \%)$ & $0(0 \%)$ & $1(12.5 \%)$ & $0(0 \%)$ & $0(0 \%)$ & $8(30 \%)$ \\
\hline Bachelor degree & $3(60 \%)$ & $4(80 \%)$ & 20 (95\%) & $1(12.5 \%)$ & $0(0 \%)$ & $0(0 \%)$ & $17(63 \%)$ \\
\hline Master's degree & $0(0 \%)$ & 1 (20\%) & $1(5 \%)$ & 5 (62.5\%) & $0(0 \%)$ & $0(0 \%)$ & $2(7 \%)$ \\
\hline Doctorate & $0(0 \%)$ & $0(0 \%)$ & $0(0 \%)$ & $1(12.5 \%)$ & $5(100 \%)$ & $11(100 \%)$ & $0(0 \%)$ \\
\hline
\end{tabular}

\section{Data analysis}

All individual interviews and focus groups were audio taped. These audiotapes were integrally transcribed and reviewed. To protect privacy of participants, no nominal or other data that could identify them was transcribed. Participants' transcripts were identified by a number, group (1 through 8), and province (Quebec or Nova Scotia).

Transcripts were matched with the concepts of both bi-dimensional professional navigation framework and focused evaluation process. Indeed, in order to encompass the diversity of the functions of professional navigators, the data analysis followed the two dimensions of the professional navigation framework (Fillion et al., 2012). Working with NVivo7 ${ }^{\varpi}$ program, descriptive codes were created by attributing a code to each unit of analysis (words, phrases or paragraphs) highlighting an issue. Merging of similar descriptive codes created thematic categories representing a set of conceptual components. Analysis was carried out applying the approach of Strauss and Corbin (1990). A constant-comparative process of data analysis occurred within the research team on an ongoing basis to ensure data saturation and to contribute to confidence in the validity of the analysis. By analysing data according to each province through this inductive and deductive comparison process, similarities and differences emerged among the two models of professional navigation and contributed to improving our understanding of cancer navigation.

\section{Results}

A total of 100 volunteers participated in this study: the PNO group $(n=21)$ and the CPN group $(n=5)$; the medical oncology specialists group (lung specialist, oncologist, urologist, radiationoncologist, psychiatrist) $(n=5)$; the family physicians group $(n=11)$; the other oncology workers group interacting with PNOs (nurses, social workers, community resources workers and coordinators,

\begin{tabular}{|c|c|}
\hline & $\begin{array}{l}\text { Cancer patients and their } \\
\text { significant others }(n=18)\end{array}$ \\
\hline \multicolumn{2}{|l|}{ Gender } \\
\hline Women & $11(61 \%)$ \\
\hline Men & 7 (39\%) \\
\hline Age, $M(S D)$ & $61.00(12.47)$ \\
\hline \multicolumn{2}{|l|}{ Education } \\
\hline Secondary school not completed & $2(11 \%)$ \\
\hline Secondary school & 7 (39\%) \\
\hline Professional diploma (Quebec) & $1(6 \%)$ \\
\hline College (Quebec) & $6(33 \%)$ \\
\hline Bachelor degree & $2(11 \%)$ \\
\hline Master's degree & $0(0 \%)$ \\
\hline Doctorate & $0(0 \%)$ \\
\hline
\end{tabular}

psychologist, occupational therapist, physiotherapist, nutritionist) $(\mathrm{n}=27)$; the administrative management group interacting with PNOs from Quebec $(n=8)$ and interacting with CPNs from Nova Scotia $(n=5)$; and the group of cancer patients having received services from PNOs $(n=13)$ and their significant others $(n=5)$ (see table 2 and table 3 for details). 
Facilitating continuity of care Informational continuity

According to the majority of participants, professional navigators from both provinces share timely and tailored information and advice with cancer patients and other providers from interdisciplinary team(s). By working closely with them, they contribute actively to improve informational continuity. They have been identified as key informants by patients, and also by different care providers and administrators. However, professional navigators and managers from both provinces have expressed a will to improve informational continuity with the implementation of systematic transfer mechanisms and with the use of diverse strategies like case conferencing, video conferencing, and telehealth support. In both provinces, the absence of available electronic charts was identified as a barrier to informational continuity. Currently, information is transmitted through traditional channels (verbally, notes in medical records, fax, telephone), without any concerted or systematic mechanisms.

For the initial needs assessment, PNOs and CPNs have access to a standardized assessment tool. Both groups said that this instrument is useful, but presents limitations. The tool is described as too lengthy, time consuming, only restricted to the first stage of the continuum and not necessarily suitable for all cancer patients by PNOs and CPNs. Transfer of information was also described as challenging in both provinces, but differed in the following. In Quebec, PNOs generally record the information on the patients in hospital medical files, to which every member of the specialized team has access. In Nova Scotia, it was reported that other professionals do not have access to the CPN's charts because they are kept in their offices which is an important barrier to informational continuity between health professionals. In short, both PNOs and CPNs were involved in informational continuity. Needs assessment appeared as a key function, but was associated with tools limitation.

\section{Management continuity}

Professional navigators from both models facilitate management continuity in screening, assessing unmet needs, and matching them with services and resources available within the cancer care organization and the community. Their partnerships and networks contribute to bridging many gaps. For screening and assessment, they reported again their own need for more practical and comprehensive screening and assessment tools that can be carried throughout the continuum of care, transferred to other professionals and used to structure care and referrals in a more efficient way.

In order to screen and assess as early as possible, professional navigators, in both cases, need to receive early referrals from physicians, nurses, social workers, pharmacists and other professionals, as well as self-referrals from patients themselves or their family members. There was no systematic referral process. Some navigators had to track down cancer patients, which was taking too much time away from their other responsibilities and duties time during the course of the day. Both navigators expressed the opinion that management continuity should start as early as possible in the cancer continuum and referral mechanisms to navigators need to be improved.

In addition to screening, in both cases, navigators described mapping the cancer trajectory, indicating available services along the journey, and matching unmet needs to resources as key components of management continuity. Being in the community, CPNs were well placed so as to inform their patients about community services. They were, however, less integrated in formal oncology teams compared to PNOs. Mapping the continuum of care or explaining the care plan was sometimes a challenge. On their side, PNOs (based in a supraregional team and specialized on one cancer site), were more easily able to elaborate and map the cancer care trajectory. When information related to community resources was needed, PNOs sometimes had to refer the patients to the liaison nurse or to a social worker. Depending on their location, mechanisms to match unmet needs and resources differed.

\section{Relational continuity}

Professional navigators initiate and maintain an ongoing relationship, and remain present throughout all of the stages of the care trajectory, as long as cancer patients need their support. In both cases, professional navigators were accessible, during business hours, from Monday through Friday. However, with increasingly new cases, follow-ups and unexpected crises, accessibility was sometimes reported as a concern. The caseload issue forced navigators to limit home visits in Nova Scotia and to redefine access criteria in Quebec. Moreover, most of them described limited privacy (space), as a physical barrier for relational continuity.

In terms of relational continuity, some differences were reported. PNOs were especially active during the treatment phase compared to CPNs. The role of the CPN often started earlier, in the community and around diagnosis, their role becoming more important at the end of the treatment phase, when patients were transitioning back to the community.

Relational continuity starts with a good therapeutic relationship. Even if the implication of professional navigators may vary depending of their location, both PNOs and CPNs were accessible throughout the cancer journey. Both were actively involved near the beginning and at the end of treatments, two critical transitions on the cancer continuum.

\section{Promoting patient and family empowerment Active coping}

This part of the professional navigator role was reported as similar for both studied cases. Professional navigators described how they enabled cancer patients to meet their practical and social needs by assisting them to actively obtain needed information, support, and referrals. They were empowering the patient by directing them to the appropriate resources without doing the process for them. Several cancer patients and family members confirmed that their professional navigators helped them to do tasks or activities by themselves. Professional navigators assist them to solve problems or manage distress (e.g., identifying the problem, exploring solutions, facilitating the choice of one solution, coaching for implementation, and assisting in appraising the relevance of that solution). They provide information that helps patients make informed decisions about lifestyles changes, supporting patients and family members in decision making through cancer transitions, especially when they transition to palliative care.

Professional navigators recognized psychosocial interventions as key functions of their role. In both cases, however, they did report some challenges in this domain. They reported that they would benefit from training specifically on: how to motivate patients regarding behavioural changes, how to promote self-care, and also how to intervene with sexual and spiritual issues.

\section{Cancer self-management}

Both groups of navigators were actively involved in facilitating cancer management. They enable better self-management, notably by assessing and monitoring symptoms, by providing or facilitating symptom management, as well as by assisting and reinforcing the patient in adjusting to and managing their altered health state and symptoms pro-actively, not reactively, through timely and tailored information and self-care instructions. Professional navigators have an advocacy role, as they support patients and families on how to negotiate care. With navigation assistance, patients felt better prepared and able to cope with their cancer and trajectory of care, which was corroborated by professional navigators and specialized medical doctors. Being more involved during the treatment phases, PNOs were actively engaged in symptom management.

\section{Supportive care}

Professional navigators emphasized the fact that with their functions of evaluation, screening, assessment, direct care or intervention and referrals, they were improving access to supportive care 
for cancer patients and their families. More precisely, screening for distress and conducting comprehensive supportive care needs and resources assessment were reported again as key functions for providing supportive care, for both CPNs and PNOs. Evaluation was guiding navigators on how to support patients and families in identifying and addressing their unmet needs more efficiently.

\section{Discussion}

The objective of this study was to compare two well-implemented cases of professional navigators from Quebec and Nova Scotia.

Some differences were noted and are, for the most part, linked with the settings and teams in which navigators work. Indeed, application of the role may differ between navigators integrated in formal oncology teams and based in a tertiary care hospital (most PNOs in Quebec), and navigators based in the community, not integrated in a formal oncology team (most CPNs in Nova Scotia).

However, several similarities were noticed, notably the fact that the professional navigators were registered oncology nurses and available throughout the cancer care trajectory. As reported in previous works, professional navigators differ from other oncology professionals and specialized oncology nurses in terms of their scope of practice (Cook et al., 2010), particularly by being involved at different phases on the cancer trajectory, and not limited to a particular sector of oncology practice such as surgery, radiation or chemotherapy. They play a crucial role in facilitating transitions along the cancer care continuum and in sustaining relational continuity throughout the whole cancer journey by being there for the patients and their families from their diagnosis, through treatments, relapses to end-of-life care (Cancer Care Nova Scotia, 2004; de Serres \& Beauchesne, 2000; Fillion et al., 2012; Tremblay, 2008). In addition, results show that professional navigators in both provinces face similar challenges in performing their roles, in order to facilitate continuity of care and promote patient and family empowerment.

\section{Continuity of care}

In this study, PNOs and CPNs described their role in informational continuity. Needs assessment was presented as key function, and was associated with tools limitation that will be further discussed later. Transfer of information was also described as challenging, even more when the assessment conclusions were not integrated in medical records. There was clearly a need to improve the effectiveness with which information was transferred to a navigator's file (lack of standardized communication tool, e.g. e-chart). The follow-up period after the end of treatments was particularly challenging for continuity of information. To improve this, implementing the use of survivorship care plans can be proposed (Earle, 2006; Institute of Medicine [IOM], 2006).

Our results also indicate that PNOs and CPNs were strongly involved in management continuity. Addressing information needs, mapping the cancer trajectory, and matching unmet needs to appropriate resources were described in both cases as key functions (Bowman \& Grim, 2008; Wilcox \& Bruce, 2010). Differences in the ways of linking mechanisms to match unmet needs and resources were noticed, but professional navigators in Quebec and Nova Scotia were facing similar challenges. They had to deal with the development of coherent and timely coordination of services at a period when interdisciplinary care plan and formal community partnerships (shared-care approaches), two strategies recommended by the IOM (2006), were not yet available.

In both cases, navigators actively contributed to the improvement of interprofessional collaboration. To do so, they first had to promote their navigators' role, which is also an emerging practice in oncology. The importance of the continuity of care role for professional navigators, as well as the challenges incidental to it, have been described in previous work (CPACC, 2010; Doll et al, 2007; Fillion et al., 2012; Plante \& Joannette, 2009b; Tremblay, 2008). Thus, it is recommended to identify clearly and define overlaps perceived by people working with professional navigators, and to promote and clarify this key role to the patient and to the interprofessional team.

Finally, our results illustrate in both cases the importance of the professional navigators' role in relational continuity, which is starting with the establishment of a therapeutic relationship. Even if the intensity of the implication of professional navigators may vary depending of their location, both PNOs and CPNs were accessible throughout the cancer journey. Hence, the navigators' role appears to be a key function (CPACC, 2010; de Serres \& Beauchesne, 2000; Fillion et al., 2012; Haggerty et al., 2003; Wilcox \& Bruce, 2010). Both PNOs and CPNs were actively involved near the beginning and the end of treatments, two critical transitions on the cancer continuum. The support provided at these two vulnerable periods of time contributes to the relational continuity.

\section{Patient and family empowerment}

In terms of empowerment, our results demonstrated that all professional navigators used psychosocial interventions to reinforce active coping strategies. Psychosocial interventions constitute key functions of their role to help patients and families in their adaptation process to a variety of life changes related to cancer. However, both PNOs and CPNs trained in oncology nursing, reported that they sometimes lack expertise in specific areas of this domain of care. They could benefit from receiving psychosocial oncology training (CPACC, 2010; Tremblay, 2008).

Our results also illustrated how both professional navigators enable better cancer management in a similar way. They contribute to this outcome by assisting and reinforcing the patient in adjusting to and managing their altered health state and symptoms proactively, not reactively, through timely and tailored information and self-care instructions (Fitch, 2008). Indeed, with the help of professional navigators, patients' understanding increases, their anxieties decrease, they develop tools to cope with their difficulties, and they feel more empowered to focus their energy on getting well and taking back control of their life (Wilcox \& Bruce, 2010).

Our results also highlighted some differences between cases in terms of symptom management. The PNOs were more active during treatments. Being based, for the most part, in hospital settings, they were able to respond more directly to the patient's symptoms. In Nova Scotia, patients treated in cancer centres have appointed cancer nurses, which take on most of the symptom management. The difference observed between the cases in terms of symptom management can thus be explained in terms of a difference in care organization, rather than in terms of role distinction.

Finally, in terms of facilitating access to supportive care, our results demonstrate the importance of screening for distress and conducting comprehensive supportive care needs and resources assessment. In both cases, these assessment tasks, which combined tools and narrative interviews, were presented as key functions for supportive care. Recent literature reviews also describe tools or ways of combining the questionnaire and clinical interview in order to better target clinical objectives (Wen \& Gustafson, 2004; Richardson, Sitzia, Brown, Medina \& Richardson, 2005).

\section{Tools and training}

All the previously mentioned challenges reveal the necessity of improving tools and training, for both dimensions of the role in each model. Indeed, at the time of data collection, professional navigators from both Quebec and Nova Scotia were looking for practical tools that could be carried throughout the continuum of care, be transferred to other professionals and be used to structure care and referrals in a more efficient way. Current efforts to implement systematic distress screening tools with patient navigators should contribute to answer this need (CPACC, 2009) and should, therefore, be 
documented. The implementation of a systematic distress screening tool with patient navigators from Quebec and Nova Scotia has been discussed in a recent article (Fillion et al., 2011). In brief, it is recommended that clinicians and organizations develop tools that meet patient navigators' needs and would facilitate their role (e.g. computerized tools to facilitate coordination of care, official procedures to facilitate informational continuity, referral procedures close to diagnosis, screening for distress tool, comprehensive and focused assessment tools that are concise and functional and could be used all along the continuum, economic impact indicators of professional navigators on the health system, and strategies to diminish professional navigators' clerical tasks).

Concerning training, efforts were made in each province in order to assure that all professional navigators receive adequate training. In Quebec, all PNOs had to meet the objectives of the Direction de la lutte contre le cancer (DLCC's) training program (DLCC, 2007) and to participate in ongoing training. In Nova Scotia, the CPN program was supported by Cancer Care Nova Scotia, which enables the CPNs to have access to continuing education based on their needs. For example, when CPNs had to extend their scope of practice in psychosocial care, education interventions were planned to support the expansion. Our results suggest that the base and ongoing curriculum training for professional navigators should be enhanced in order to better prepare them to fully play their role, particularly concerning psychosocial care, given that in the two studied models, all navigators had a nursing background.

\section{Limitations}

The majority of participants were supporters of the professional navigation role. This constitutes a first limitation. In addition, the sample was not equally separated between Quebec and Nova Scotia. However, the data collected in Nova Scotia with CPNs and managers confirmed and contributed to nuance the data collected in Quebec with the other groups of participants. Indeed, it can be said that using the professional navigation framework of Fillion et al. (2012) was relevant to identify and analyze differences between Quebec and

\section{REFERENCES}

Bowman, S.C. \& Grim, R.D. (2008). The efficacy of the nurse navigator in a community hospital breast care program. Seminars in Breast Disease, 11(1), 26-30. doi:10.1053/j.sembd.2008.04.007

Bulsara, C., Styles, I., Ward, A.M. \& Bulsara, M. (2006). The psychometrics of developing the patient empowerment scale. Journal of Psychosocial Oncology, 24(2), 1-16. doi:10.1300/ J077v24n02_01

Canadian Association of Nurses in Oncology. (2006). Practice standards and competencies for the specialized oncology nurse. Retrieved from http://www.cano-acio.ca/conep/

Canadian Partnership Against Cancer Corporation. (2010, January). Guide to implementing navigation [Working copy]. Retrieved from http://www.partnershipagainstcancer.ca/sites/default/ files/Guide_Implementation_Navigation.pdf

Canadian Partnership Against Cancer Corporation (CPACC). (2009, May 21). Guide to Implementing Screening for Distress, the $6^{\text {th }}$ Vital Sign. Moving Towards Person-Centered Care. Part A: Background, Recommendations, and Implementation [Working Copy]. Retrieved from http://www.partnershipagainstcancer.ca/ sites/default/files/Guide_CJAG.pdf

Cancer Care Nova Scotia. (2004, March). Cancer patient navigation evaluation findings. March final report. Retrieved from http:// www.cancercare.ns.ca/en/home/publications/reports.aspx

Carver, C.S., Scheier, M.F., \& Weintraub, J.K. (1989). Assessing coping strategies: A theoretically based approach. Journal of Personality and Social Psychology, 56(2), 267-283. Retrieved from http:// www.psy.miami.edu/faculty/ccarver/documents/p89COPE.pdf
Nova Scotia's models of professional navigation. Its transferability is conceivable to study other models of cancer navigation (Huberman \& Miles, 1991; Mukamurera, Lacourse \& Couturier, 2006).

\section{Implications}

Professional navigation offers answers to some continuity issues, while promoting patient and family empowerment. Our results support and illustrate the bi-dimensional nature of this role in two provinces. Our results also suggest, however, that this role needs to be well defined and understood by the oncology team members and by the navigators themselves. This role is not simply a "patch" or "band-aid" for whatever is not working well in any given setting. In fact, in describing the barriers in the continuity of care that is provided to the patients, such as absence of systematic transfer mechanisms and electronic charts, tools limitations, lack of integration in formal oncology teams, limited physical spaces and accessibility of navigators due to increasingly large caseloads, the results contribute to a better understanding of what is not working well and how it can be remedied. Acknowledgement of a comprehensive navigation framework by decision makers, managers and clinicians could lead to the development of similar roles with other diseases like diabetes or cardiac diseases. Future work could look at implementing navigation in other settings and for populations suffering from these chronic diseases, and see if a bi-dimensional conceptual model of patient navigation can also be applied.

\section{Conclusion}

Differences between different professional navigators' models or applications can be explained by the different characteristics of the settings in which they are working but, overall, they have very similar functions and achieve similar outcomes. For instance, nurse navigators can be integrated in a specialized oncology team or in the community but, no matter the setting, their role has to be positioned in an integrated network of care and services where the patient is at the centre. This could contribute to improving quality and continuity of cancer care

Cook, S., Fillion, L., Veillette, A.-M., Cook, S., de Serres, M., Doll, R., \& Kazanjian, A. (2010, May). Scope of practice and associated competency requirements for professional cancer patient navigators. Symposium conducted at the IPOS $12^{\text {th }}$ World Congress of Psycho-Oncology, Quebec City, Quebec, Canada/ Psycho-Oncology, 19(Suppl. S2), S12.

de Serres, M., \& Beauchesne, N. (2000). L'intervenant pivot en oncologie, un rôle d'évaluation, d'information et de soutien pour le mieux-être des personnes atteintes de cancer [The case manager in oncology: An assessment, information-giving, and support role for the well being of people affected by cancer]. Retrieved from http://publications.msss.gouv.qc.ca/acrobat/f/ documentation/2000/00-908.pdf

Direction de la lutte contre le cancer (DLCC). (2007). L'infirmière pivot en oncologie. Programme de formation [The oncology pivot nurse. Training program]. Retrieved from http://www.msss. gouv.qc.ca/sujets/prob_sante/cancer/download.php?f=f3ca389c eab25385666e2f00e2af485f

Doll, R., Barroetavena, M.C., Ellwood, A.L., Fillion, L., Habra, M.E., Linden, W., \& Stephen, J. (2007). The cancer care navigator: Toward a conceptual framework for a new role in oncology. Oncology Exchange, 6(4), 28-35. Retrieved from http://www. oncologyex.com/gif/archive/2007/vol6_no4/6_continuing_care_ 4.pdf

Earle, C.C. (2006). Failing to plan is planning to fail: Improving the quality of care with survivorship care plans. Journal of Clinical Oncology, 24(32), 5112-5116. doi:10.1200/JCO.2006.06.5284 
Fillion, L., Cook, S., Blais, M.-C., Veillette, A.-M., Aubin, M., de Serres, M., ... Fournier, B. (2011). Implementation of screening for distress with professional cancer navigators. Oncologie, 13, 277 289. doi:10.1007/s10269-011-2026-8

Fillion, L., Cook, S., Veillette, A.-M., de Serres, M., Aubin, M., Rainville, F., ... Doll, R. (2012). Professional navigation framework: Elaboration and validation in a Canadian context. Oncology Nursing Forum, 39(1), E58-E69. doi:10.1188/12.ONF.E58-E69

Fillion, L., de Serres, M., Lapointe-Goupil, R., Bairati, I., Gagnon, P., Deschamps, M., ... Demers, G. (2006). Implementing the role of patient-navigator nurse at a university hospital centre. Canadian Oncology Nursing Journal, 16(1), 11-17.

Fitch, M.I. (2008). Supportive care framework: Theoretical underpinnings. In M.I. Fitch, H.B. Porter, \& B.D. Page (Eds.), Supportive care framework: A foundation for person-centered care (pp. 11-29). Pembroke, Ontario: Pappin Communications.

Haggerty, J.L., Reid, R.J., Freeman, G.K., Starfield, B.H., Adair, C.E., \& McKendry, R. (2003). Continuity of care: A multidisciplinary review. BMJ, 327(7425), 1219-1221. doi:10.1136/bmj.327.7425.1219

Huberman, M., \& Miles, M.B. (1991). Analyse des données qualitatives: Recueil de nouvelles méthodes [Qualitative data analysis: A sourcebook of new methods]. Bruxelles, Belgium: De Boeck Université.

Institute of Medicine (IOM). (2006). From Cancer Patient to Cancer Survivor: Lost in Transition. Retrieved from http://www.nap.edu/ openbook.php?isbn=0309095956

Lantz, P.M., Keeton, K., Romano, L., \& Degroff, A. (2004). Case management in public health screening programs: The experience of the national breast and cervical cancer early detection program. Journal of Public Health Management and Practice, 10(6), 545-555.

Mukamurera, J., Lacourse, F., \& Couturier, Y. (2006). Des avancées en analyse qualitative: Pour une transparence et une systématisation des pratiques [Advances in qualitative analysis: For more transparent and systematic practices]. Recherches Qualitatives, 26(1), 110-138. Retrieved from http://www.recherche-qualitative. qc.ca/numero26(1)/mukamurera_al_ch.pdf

Parker, V.A., Clark, J.A., Leyson, J., Calhoun, E., Carroll, J.K., Freund, K.M., \& Battaglia, T.A. (2010). Patient navigation: Development of a protocol for describing what navigators do. Health Services Research, 45(2), 514-531. doi:10.1111/j.1475-6773.2009.01079.x

Patton M.Q. (1997). Utilization-focused evaluation: The new century text (3rd ed.). Thousand Oaks, CA: Sage Publications.
Plante, A., \& Joannette, S. (2009a). L'intégration des infirmières pivots dans les équipes d'oncologie en Montérégie: Un aspect de l'implémentation du Programme de lutte contre le cancer, Partie 1 [Montérégie Comprehensive Cancer Care Centre: Integrating nurse navigators in Montérégie's oncology teams: One aspect of implementing the Cancer Control Program-Part 1]. Canadian Oncology Nursing Journal, 19(1), 13-18.

Plante, A., \& Joannette, S. (2009b). Centre intégré de cancérologie de la Montérégie: L'intégration des infirmières pivots dans les équipes d'oncologie en Montérégie: le processus. Partie 2 [Montérégie Comprehensive Cancer Care Centre: Integrating nursing navigators in Montérégie's oncology teams: The processPart 2]. Canadian Oncology Nursing Journal, 19(2), 72-77.

Richardson, A., Sitzia, J., Brown, V., Medina, J., \& Richardson, A. (2005). Patients' needs assessment tools in cancer care: Principles and practice. London: King's College London.

Skrutkowski, M., Saucier, A., Eades, M., Swidzinski M., Ritchie, J., Marchionni, C., \& Ladouceur, M. (2008). Impact of a pivot nurse in oncology on patients with lung or breast cancer: Symptom distress, fatigue, quality of life, and use of healthcare resources. Oncology Nursing Forum, 35(6), 948-954. doi:10.1188/08.ONF.948-954

Strauss A.L., \& Corbin J.M. (1990). Basics in qualitative research: Grounded theory procedures and techniques. Newbury Park, CA: Sage Publications.

Thorne, S., \& Truant, T. (2010). Will designated patient navigators fix the problem? Oncology nursing in transition. Canadian Oncology Nursing Journal, 20(3), 116-121.

Tremblay, D. (2008). La traduction d'une innovation organisationnelle dans les pratiques professionnelles de réseau : L'infirmière pivot en oncologie [The translation of an organizational innovation into network professional practices: The oncology pivot nurse](Doctoral dissertation, Université de Montréal, Québec, Canada). Retrieved from http://proquest.umi.com/pqdlink?Ver=1\&Exp=10-19-2015 $\& \mathrm{FMT}=7 \& \mathrm{DID}=1868855981 \& \mathrm{RQT}=309 \&$ attempt $=1 \& \mathrm{cfc}=1$

Wen, K.Y., \& Gustafson, D.H. (2004). Needs assessment for cancer patients and their families. Health and Quality of Life Outcomes, 2, 11. doi:10.1186/1477-7525-2-11

Wilcox, B., \& Bruce, S.D. (2010). Patient navigation: A «win-win» for all involved. Oncology Nursing Forum, 37(1), 21-25. doi:10.1188/10. ONF.21-25

Yin, R.K. (1994). Case study research. Design and methods (2nd ed.). London: Sage Publications.

\section{Appendix 1: Focus group guidelines}

\section{FOCUS GROUP Discussion guide}

For a 6- to 8-participant group, which comprises CPNs and other professionals working with CPNs.

- Introduction of the presenter and her assistants.

- Introduction of the research.

- Going around the table.

- Presenting the objectives of the group discussion.

- Explain the approach, duration, instructions, and have the consent form read and signed.

The approach: discussion to focus on the following themes :

1. Input, reactions; why were CPNs implemented?

2. Access, action, collaboration; roles of CPNs.

3. Effect or impacts of CPNs.

Duration: 2 hours at max.

Give instructions.

Obtain signature on the consent form. 
Start with the technique of word associations (words associated with: Cancer Patient Navigator or CPN).

1. Input/Reactions

Why have CPNs been implemented in Nova Scotia?

- Who were in charge of this innovation?

- What were the main objectives in developing and in implementing this new role in oncology?

- Who was the target population of this innovation?

- What are the main problems faced by this population?

- Why do you think they've decided to implement CPN as a solution?

- Do you think that this solution is appropriate to solve the main issues faced by this population?

When and how was the role implemented in your district?

- What about the field preparation before the implantation of the innovation?

- Did people of your organization believe in its relevance and usefulness from the beginning?

- Now, how well is the CPN role perceived?

- What do you think about the relevance of this role?

2. Access/Actions/Collaboration

Is the targeted population reached, and how?

- Where along the cancer continuum, can cancer patients have access to the CPN?
$\square$ Diagnosis
$\square$ Beginning
$\square$ Treatment
$\square$ Offset
$\square$ Post treatment

- How do the links between CPN and cancer patient happen? Is she contacting them? Where is she located? Does she go to patients' homes? Do they use phone calls? Other means of communication?

What are the main functions or roles of the CPN?

EMPOWERING (Patient needs centred)

- What does the CPN do for empowering patients? How?

- ASSESSMENT-SCREENING-TRIAGE- REFERENCE (HOW)

- EMOTIONAL SUPPORT (HOW)

- INFORMATION (HOW)

- OTHER (e.g. Symptom management)

CONTINUITY OF CARE

- How the CPN is contributing to the improvement of continuity of care

- INFORMATION (about the patient: global information: biopsycho-social and spiritual)

- TREATMENTS or MEDICAL APPROACHES? (coordination of care; seamless care trajectory)

- RELATIONSHIP (easy access to the same persons along all the cancer care continuum)

What does she do at two critical transitions of the cancer care continuum?

- Around diagnosis

- At the end of the medical treatments

What resources or support help the CPN to do her functions?

- Which resources are available to assist her in her functions (assessment tools, screening, documentation, file access)

- If the CPN faces a problem, what can she do?

Who are her main partners and how is the collaboration with them?

- In the community: family physicians, local hospital, community organizations

- In the cancer centre

What is facilitating her role and her functions?

What is hindering her role and her functions?

- Having to do tasks not related to her previous functions

- Lack of resources

3. Effects or Impacts

What are the consequences of having a CPN?

- For the patients and families

- Emotional support

- Information and other needs

- Access to services, resources in a timely fashion

- Preparation for next steps along the continuum

- Satisfaction and quality of life

- For continuity of care

- Circulation of information about the patient (in such a way that patient does not have to tell his story again and again)

- Communication among organizations

- Communication between health providers (professional collaboration)

- Communication between cancer centre and primary care

- Between family physician and patient

- Between family physician and cancer team members

What do you think about long-term effects related to this CPN on the health care system? 
Appendix 2: Individual interview guidelines

\section{Discussion guide for interview with Cancer Patient Navigators (CPN)}

\section{Inputs}

From your perspective, what were the main objectives in developing and implementing the CPN role in oncology?

- Who was in charge of the implementation of the CPN's role in Nova Scotia?

- Who was the target population?

- What are the main issues faced by this population?

- Given these issues, why do you think it was decided to implement the CPN role?

- Do you think that this role is appropriate to address the main issues faced by this population?

- When was the role implemented in your district?

- What sort of preparation occurred before the implementation of CPN?

- When were the people from your organization informed about the implementation of the CPN role?

- How were they informed?

- Do you think that they received enough information about the CPN's role? Is there any information that they should have received that they didn't?

- Did people in your organization and other stakeholders believe in its relevance and usefulness from the beginning?

- How is the CPN role perceived now?

- What are your feelings about the relevance of this role?

\section{Actions}

From your perspective, what are the main functions or roles of the CPN?

CLINICAL FUNCTIONS

- Does the CPN empower patients? How?

ASSESSMENT-SCREENING-TRIAGE-REFERENCE

- As a CPN, do you assess the needs of the cancer patient and his or her significant others?

- At what point(s) along the care trajectory do you assess their needs? (Diagnosis? End of treatments?)

- Do you use specific tools?

- Who has access to your assessments or notes? How do they access this information?

- Are the assessments useful? Could they be improved?

SUPPORT

- Do you provide support to cancer patients? How?

- What type of support do you provide? (Emotional support, practical or instrumental to solve concrete problems, spiritual support, other type of support) How do you provide this support?

- What type of skills does a CPN need to possess to support cancer patients and their significant others?

- As a CPN, are you supported by a psychosocial and spiritual oncology team?

- How do you collaborate with other professionals working in this psychosocial oncology team?

INFORMATION

- Do you provide information to cancer patients and their significant others? If so, what type of information? How do you provide it? OTHER CLINICAL FUNCTIONS

- Do you provide other clinical functions? (Symptoms management, referrals)

- How much of your practice is devoted to clinical duties? Do you have enough time to complete these duties?

\section{COORDINATION FUNCTIONS, CONTINUITY OF CARE}

- Is the CPN contributing to the improvement of continuity of care? How? (Coordination of care) INFORMATION

- Is the CPN contributing to the sharing of information, so the cancer patient does not have to repeat his or her story again and again? How?

TREATMENTS or MEDICAL APPROACHES

- Is the CPN contributing to the coordination of care? (seamless care trajectory)

RELATIONSHIP

- Do you think that cancer patients and family members can easily access a CPN along the cancer care continuum?

Among the CPN's functions, do you think that some are more prevalent than others?

As a CPN, do you have to perform tasks that are not part of your role?

From your perspective, what is facilitating the CPN's role and functions?

And what is hindering your role and functions?

\section{Participation}

From your perspective, is the targeted population being reached?

- How, as a CPN, do you link with cancer patients? Do you contact them? Which means of communication do you use?

- How are cancer patients referred to CPNs?

- When along the cancer care continuum can cancer patients have access to the CPN?

(Diagnosis-Pre Treatment-Treatment-Post Treatment-After treatment)

- There are two critical transitions along the cancer care continuum: the diagnosis phase and the post treatment phase. What does the CPN do at each of these phases? 
How, as a CPN, do you collaborate with other health care providers and community groups?

- Where are you located?

- Do you go to your patients' homes?

- Are you a member of an oncology team? How are you integrated with cancer care?

- Are there actions that have been undertaken to facilitate your integration in this team?

- As a CPN, who are your main partners and how do they collaborate with you?

- In the Cancer Centre

- Are there other cancer patient navigators there?

- How do you communicate with them?

- What is helping this inter-navigator communication?

- What makes it a challenge?

- In the local hospitals

- With family physicians

- How do you communicate with them?

- What is helping the communication?

- What makes it a challenge?

- In the community, with community organizations

- Are there other professionals working with you? (Social workers, psychologists, pharmacists)

- How do they access you? Do they contact you?

As a CPN in your organization, how do you use the available resources?

- What resources do you have to facilitate your clinical functions and your navigation role? (Reference tools, assessment tools, documentation, access to files)

- Do you have enough resources?

- If you face a problem, what resources are available to you?

- Are you supported in your clinical functions? To whom can you refer to?

- Are you supported in you coordination functions? To whom can you refer to?

- Can you adapt your services (resources) to your cancer patient's needs?

\section{Reactions}

What do you think about the relevance of this role in cancer care for...?

- The cancer patient and their family members

- Oncologists and other cancer team members

- Family physicians of cancer patients

- Is this role useful for any other person or patient population?

\section{Effects on cancer patients}

From your perspective, what are the consequences of having a CPN for the patient and for his or her family?

- Do you think that CPNs contribute to a patient's empowerment?

- How? (Solving problems, capacity building, coping, perception of personal efficacy, stress reduction, well-being, quality of life)

- Do you think that other caregivers see the cancer patient and his or her family as being better prepared to manage their cancer journey as a result of the CPN's involvement in their care? (treatment or follow-up)

Do you see other positive effects of the CPN on patients and families?

Do you see any negative effects of the CPN on patients and families? If so, what are they?

6. Effects on health system and continuity of care

From your perspective, what are the impacts of the CPN role on the health system?

- Does the CPN facilitate interdisciplinary team work among health providers? How?

- Does the CPN contribute to better communication (sharing of information) among organizations, or between the cancer centre and primary care?

- What are the consequences of the CPN role on the relationship:

- Between health providers? (Professional collaboration)

- Between family physician and cancer team members?

- Between family physician and cancer patient?

- Do you think that CPNs contribute to improving the coordination of care?

- Do cancer patients seem to have a better understanding of the complex cancer care system?

- Do they have better access to supportive care and other services?

- Is the CPN contributing to a better understanding of their cancer care trajectory?

- Is the CPN helping to improve patients' satisfaction with cancer care?

- Do you think that the CPN offers a consistent point of contact for patients? How?

- Do you think that the CPN becomes a point of reference for the patient? (a safety net)

Do you see other positive effects of the CPN role on the health care system?

Do you see negative effects of the CPN role on the health care system?

7. Other effects or impacts

What do you see as the long-term effects and challenges of the CPN role on the health care system? (Positive or not)

Other comments

End of interview-Thank you (:) 